\title{
PROPOSTA DE PROGRAMA DE PREVENÇÃO DE RISCOS AMBIENTAIS PARA UMA EMPRESA DE PEQUENO PORTE
}

\section{PROPOSAL FOR AN ENVIRONMENTAL RISK PREVENTION PROGRAM FOR A SMALL BUSINESS}

\section{Artur Alves Farias Júnior ${ }^{1}$}

RESUMO: Povoadas de detalhes e exceções, as leis trabalhistas brasileiras podem até não ser consideradas das mais simples para um entendimento rápido, mas é certo que, apesar disso, alguns termos já fazem parte do dia a dia de empregadores e empregados nas empresas e entre esses está o Programa de Prevenção de Riscos Ambientais (PPRA). O presente artigo tem por objetivo demonstrar de forma prática a aplicação de um PPRA numa empresa de pequeno porte, prestadora de serviços na construção civil, situada no município de Aracaju-Sergipe. Este trabalho, baseado nos parâmetros mínimos e diretrizes gerais estabelecidos pela Norma Regulamentadora NR-9, é resultado de uma consultoria de segurança do trabalho e meio ambiente numa empresa que, em 2018, passava a atuar em prédio próprio e buscava estabelecer medidas para redução, controle ou eliminação desses riscos em prol da preservação da integridade física dos seus colaboradores, bem como adequação à legislação e normativas.

Palavras-chave: Segurança do trabalho. Consultoria. PPRA. NR 9.

ABSTRACT: Populated with details and exceptions, Brazilian labor laws may not even be considered the simplest for quick understanding, but it is certain that, despite this, some terms are already part of the daily routine of employers and employees in companies and between these are the Environmental Risk Prevention Program (PPRA). This article aims to demonstrate in a practical way the application of a PPRA in a small company, providing services in civil construction, located in the municipality of Aracaju-Sergipe. This work, based

\footnotetext{
I Especialista em Segurança do Trabalho e Gestão Ambiental (UCAM); Técnico de Segurança do Trabalho (MTE 44677/SE); contato: arturfarias.aju@hotmail.com.
} 
on the minimum parameters and general guidelines established by the Regulatory Norm NR9 , is the result of a work safety and environmental consultancy in a company that, in 2018, started to operate in its own building and sought to establish measures for reduction, control or elimination of these risks in order to preserve the physical integrity of its employees, as well as compliance with legislation and regulations.

Keywords: Work safety. Consultancy. PPRA. NR 9.

\section{INTRODUÇÃO}

O presente trabalho tem como tema uma proposta de Programa de Prevenção de Riscos Ambientais (PPRA) para uma empresa de pequeno porte, prestadora de serviços na construção civil, em Aracaju-Sergipe. Conforme explica Chaves et al. (2009), a disponibilidade de tempo dos trabalhadores para a saúde e a segurança no trabalho, o reforço de atividades de educação e a melhor integração das equipes contribui para o sucesso dessas ações nas empresas.

Neste contexto, o objetivo do trabalho é demonstrar de forma prática a aplicação desse Programa, visando a preservação da saúde e integridade físicas de todos os envolvidos nas atividades através da antecipação, reconhecimento, avaliação e consequente controle da ocorrência de riscos ambientais existentes ou que venham a existir no ambiente de trabalho. Sendo o PPRA, observado pela NR 9 em consonância com outras normas que se fizerem necessárias, conforme explicado adiante.

As ações previstas neste trabalho foram desenvolvidas no âmbito da empresa, sob responsabilidade do empregador, com a participação dos trabalhadores, sendo sua abrangência dependente das características dos riscos e das necessidades específicas de controle do processo produtivo. Deste modo, a não divulgação do nome da empresa preserva o sigilo de sua identidade, por se tratar de uma consultoria técnica.

\section{Desenvolvimento}

A NR 9, texto aprovado pela Portaria n.o 25 de 29/12/1994 (Lei n.o 6.514, de 22 de dezembro de 1994), que estabelece a obrigatoriedade de elaboração e implementação do Programa de Prevenção de Riscos Ambientais - PPRA visa à prevenção da saúde e da integridade dos trabalhadores, através da antecipação, reconhecimento, avaliação e consequente controle da ocorrência de riscos ambientais de trabalho, existentes na empresa.

O PPRA, segundo a NR 9, tem validade de or (um) ano, quando então deverá ser reavaliado, podendo este documento ser revisado durante o período sempre que necessário. 
Entre os inúmeros riscos, observou-se os ocupacionais, porque "os seres humanos, dedicam ao trabalho, no mínimo, um terço do seu tempo e embora as inovações tecnológicas tenham reduzido riscos em alguns setores produtivos, essas também geraram novos" (ASSUNÇÃO, 2003).

Deixar as equipes decidirem a forma de condução da análise parece constituir uma vantagem, à medida que possibilita a adoção de técnicas de seu domínio, além de permitir compatibilizar com outros sistemas de informação (ALMEIDA, 2003). O que justifica, deste modo, a necessidade do PPRA ser para livre e fácil acesso por parte de toda a equipe de uma empresa.

Segundo as revisões da NR 5, primeiro deve-se verificar qual a atividade econômica da empresa, através da Classificação Nacional de Atividades Econômicas (CNAE) e posteriormente o enquadramento do respectivo Grupo com o seu número de funcionários. Isto feito, ficará determinado se há ou não necessidade de organizar e manter em funcionamento uma Comissão Interna de Prevenção de Acidentes - CIPA, composta de representantes do empregador e dos empregados. Lembrando que toda empresa deverá ter ao menos o Designado de CIPA.

A análise das condições de trabalho foi realizada por setor, considerando, função, descrição do local de trabalho, bem como, a identificação dos riscos potenciais. Sobre cada risco são sugeridas medidas de controle para eliminação e/ou neutralização. Além de monitoramento dos riscos, conforme indica a NR 5, contemplam o programa obrigatoriamente: Físicos, Químicos e Biológicos. Para esta consultoria observaram-se também riscos ergonômicos e de acidentes através de inspeções in loco nos ambientes de trabalho.

De acordo com a NR 6, a empresa deverá fornecer para os colaboradores somente EPI (Equipamento de Proteção Individual) homologados pelo MTE. O fornecimento é gratuito e obrigatório, uma vez que em alguns locais de trabalho, não é possível adotar medidas de proteção coletiva. Com isto, os EPI foram adotados para proteção contra os riscos de acidentes e/ou doenças profissionais do trabalho.

Necessário observar que a comprovação do fornecimento deve ser feita através de um "Recibo de EPI", onde deve constar a relação dos EPI entregues ao empregado, a data da entrega, orientações sobre a obrigatoriedade e o modo de uso e informações sobre as sanções impostas no caso do não uso, devidamente assinado pelo empregado, atestando o efetivo recebimento dos mesmos, conforme explica a NR 6. 
Os trabalhos em altura, conforme versa a NR 35, acima de 2 metros, são executados por profissionais capacitados, com o uso do cinto de segurança de três pontas e escadas portáteis em plenas condições de uso. Inclui-se ainda, a Proteção ao Incêndio, em consonância com NR 23. Esta NR define critérios que determinarão instalação, identificação, manuseio e operacionalidade dos dispositivos de combate contra incêndios. Requer-se a adequação desta norma para a obtenção do certificado de habite-se e na ocasião em que é realizado o seguro das instalações, por exemplo.

A seguir, classificação dos principais riscos ocupacionais em grupos, de acordo com sua natureza e a padronização das cores correspondentes. O quadro, deve integrar o documento do programa:

\begin{tabular}{|c|c|c|c|c|}
\hline Grupo I Verde & $\begin{array}{c}\text { Grupo2 } \\
\text { Vermelho }\end{array}$ & $\begin{array}{l}\text { Grupo } 3 \\
\text { Marrom }\end{array}$ & $\begin{array}{l}\text { Grupo } 4 \\
\text { Amarelo }\end{array}$ & $\begin{array}{c}\text { Grupos } \\
\text { Azul }\end{array}$ \\
\hline $\begin{array}{l}\text { Riscos } \\
\text { Físicos }\end{array}$ & $\begin{array}{c}\text { Riscos } \\
\text { Químicos }\end{array}$ & $\begin{array}{c}\text { Riscos } \\
\text { Biológicos }\end{array}$ & $\begin{array}{c}\text { Riscos } \\
\text { Ergonômicos }\end{array}$ & $\begin{array}{l}\text { Riscos de } \\
\text { Acidentes }\end{array}$ \\
\hline $\begin{array}{c}\text { Ruídos } \\
\text { Vibrações } \\
\text { Radiações } \\
\text { ionizantes } \\
\text { Radiações não } \\
\text { ionizantes } \\
\text { Frio } \\
\text { Calor } \\
\text { Pressões } \\
\text { anormais } \\
\text { Umidade }\end{array}$ & $\begin{array}{c}\text { Poeiras } \\
\text { Fumos } \\
\text { Névoas } \\
\text { Neblinas } \\
\text { Gases } \\
\text { Vapores } \\
\text { Substâncias, } \\
\text { compostos ou } \\
\text { produtos } \\
\text { químicos. }\end{array}$ & $\begin{array}{c}\text { Vírus } \\
\text { Bactérias } \\
\text { Protozoários } \\
\text { Fungos } \\
\text { Parasitas } \\
\text { Bacilos }\end{array}$ & $\begin{array}{c}\text { Esforço físico } \\
\text { intenso } \\
\text { Levantamento e } \\
\text { transporte manual } \\
\text { de peso } \\
\text { Exigência de } \\
\text { postura inadequada } \\
\text { Controle rígido de } \\
\text { produtividade } \\
\text { Imposição de } \\
\text { ritmos excessivos } \\
\text { Trabalho em turno } \\
\text { e noturno } \\
\text { Jornadas de } \\
\text { trabalho } \\
\text { prolongadas } \\
\text { Monotonia e } \\
\text { repetitividade } \\
\text { Outras situações } \\
\text { causadoras de stress } \\
\text { físico e/ou } \\
\text { psíquico }\end{array}$ & $\begin{array}{c}\text { Arranjo físico } \\
\text { inadequado } \\
\text { Máquinas e } \\
\text { equipamentos sem } \\
\text { proteção } \\
\text { Ferramentas } \\
\text { inadequadas ou } \\
\text { defeituosas } \\
\text { Iluminação inadequada } \\
\text { Eletricidade } \\
\text { Probabilidade de } \\
\text { incêndio ou explosão } \\
\text { Armazenamento } \\
\text { inadequado } \\
\text { Animais peçonhentos } \\
\text { Outras situações de risco } \\
\text { que poderão contribuir } \\
\text { para a ocorrência de } \\
\text { acidentes. }\end{array}$ \\
\hline
\end{tabular}

QUADRO r: Mapa de Riscos Ambientais

Fonte: NR 5

$\mathrm{Na}$ sequência, os quadros por setor, identificando os profissionais da empresa, para reconhecimento de riscos e suas medidas de controle existentes e propostas: 
Revista Ibero- Americana de Humanidades, Ciências e Educação- REASE

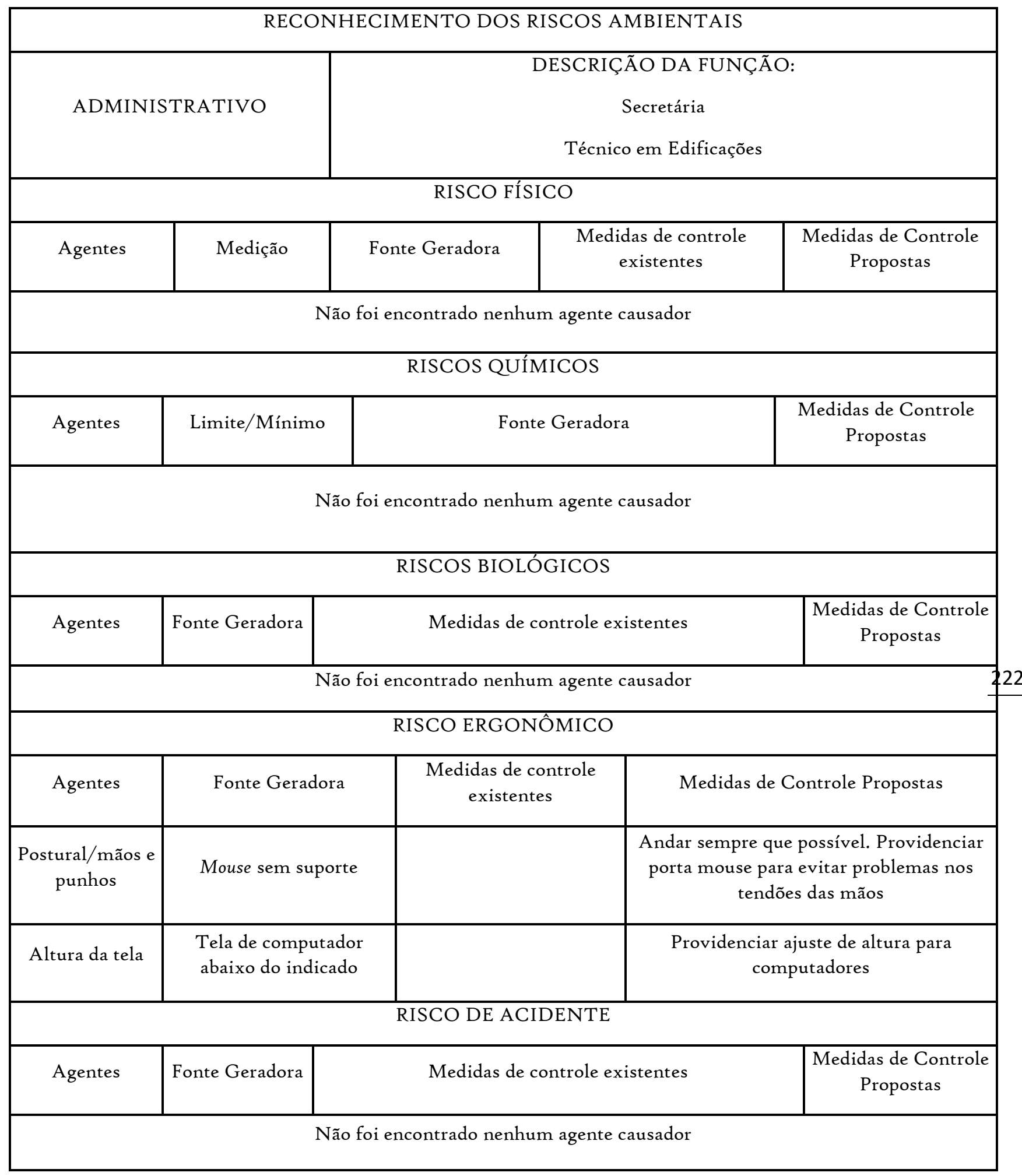

QUADRO 2: Reconhecimento de riscos setor administrativo

Fonte: Autor, 2018 


\begin{tabular}{|c|c|c|c|c|c|}
\hline \multicolumn{2}{|c|}{ OPERACIONAL } & \multicolumn{4}{|c|}{$\begin{array}{c}\text { DESCRIÇÃO DA FUNÇÃO: } \\
\text { Auxiliar de serviços gerais }\end{array}$} \\
\hline \multicolumn{6}{|c|}{ RISCO FÍSICO } \\
\hline Agente & - & Fonte Geradora & $\mathrm{Me}$ & trole & Medidas Propostas \\
\hline \multicolumn{6}{|c|}{ Não foi encontrado nenhum agente causador } \\
\hline \multicolumn{6}{|c|}{ RISCOS QUÍMICOS } \\
\hline Agentes & Limite/Mínimo & \multicolumn{2}{|c|}{ Fonte Geradora } & \multicolumn{2}{|c|}{ Medidas de Controle existentes } \\
\hline Poeira & - & \multicolumn{2}{|c|}{$\begin{array}{l}\text { Aerodispersóides comuns do ambiente } \\
\text { de trabalho }\end{array}$} & \multicolumn{2}{|c|}{$\begin{array}{l}\text { Uso de epi e não exposição } \\
\text { contínua }\end{array}$} \\
\hline $\begin{array}{l}\text { Substâncias } \\
\text { químicas }\end{array}$ & - & \multicolumn{2}{|c|}{ Manuseio de produtos de limpeza } & \multicolumn{2}{|c|}{$\begin{array}{l}\text { Uso de Epi e não exposição } \\
\text { contínua }\end{array}$} \\
\hline \multicolumn{6}{|c|}{ RISCOS BIOLÓGICOS } \\
\hline Agentes & Fonte Geradora & \multicolumn{3}{|c|}{ Medidas de controle existentes } & Medidas de Controle Propostas \\
\hline Bactérias & $\begin{array}{l}\text { Limpeza de } \\
\text { banheiros }\end{array}$ & o de Epi e cuidado & higien & & - \\
\hline \multicolumn{6}{|c|}{ RISCO ERGONÔMICO } \\
\hline Agentes & \multicolumn{3}{|c|}{$\begin{array}{l}\text { Medidas de controle } \\
\text { existentes }\end{array}$} & \multicolumn{2}{|c|}{ Medidas de Controle Propostas } \\
\hline \multicolumn{6}{|c|}{ Não foi encontrado nenhum agente causador } \\
\hline \multicolumn{6}{|c|}{ RISCO DE ACIDENTE } \\
\hline Agentes & \multicolumn{3}{|c|}{$\begin{array}{c}\text { Medidas de controle } \\
\text { existentes }\end{array}$} & \multicolumn{2}{|c|}{ Medidas de Controle Propostas } \\
\hline \multicolumn{6}{|c|}{ Não foi encontrado nenhum agente causador } \\
\hline
\end{tabular}

QUADRO 3: Reconhecimento de riscos setor operacional

Fonte: Autor, 2018 


\begin{tabular}{|c|c|c|c|c|c|c|}
\hline \multicolumn{2}{|c|}{ OPERACIONAL } & \multicolumn{5}{|c|}{$\begin{array}{c}\text { DESCRIÇÃO DA FUNÇÃO: } \\
\text { Encarregado }\end{array}$} \\
\hline \multicolumn{7}{|c|}{ RISCO FÍSICO } \\
\hline Agente & - & \multicolumn{2}{|c|}{ Fonte Geradora } & \multicolumn{2}{|c|}{$\begin{array}{l}\text { Medidas de controle } \\
\text { existentes }\end{array}$} & Medidas Propostas \\
\hline $\begin{array}{l}\text { Radiação não } \\
\text { ionizante }\end{array}$ & & \multicolumn{2}{|c|}{$\begin{array}{c}\text { Trabalho ao ar livre } \\
\text { não contínuo }\end{array}$} & \multicolumn{2}{|c|}{ Uso de protetor solar } & Ingerir bastante água \\
\hline \multicolumn{7}{|c|}{ RISCOS QUÍMICOS } \\
\hline Agentes & Limite/Mínimo & & For & Serad & & $\begin{array}{c}\text { Medidas de Controle } \\
\text { Propostas }\end{array}$ \\
\hline \multicolumn{7}{|c|}{ Não foi encontrado nenhum agente causador } \\
\hline \multicolumn{7}{|c|}{ RISCOS BIOLÓGICOS } \\
\hline Agentes & Fonte Geradora & & \multicolumn{3}{|c|}{ Medidas de controle existentes } & $\begin{array}{c}\text { Medidas de Controle } \\
\text { Propostas }\end{array}$ \\
\hline \multicolumn{7}{|c|}{ Não foi encontrado nenhum agente causador } \\
\hline \multicolumn{7}{|c|}{ RISCO ERGONÔMICO } \\
\hline Agentes & \multicolumn{2}{|l|}{ Fonte Geradora } & \multicolumn{2}{|c|}{$\begin{array}{l}\text { Medidas de controle } \\
\text { existentes }\end{array}$} & \multicolumn{2}{|c|}{ Medidas de Controle Propostas } \\
\hline $\begin{array}{c}\text { Responsabilidad } \\
\text { e }\end{array}$ & $\begin{array}{c}\text { Transporte de pess } \\
\text { malotes }\end{array}$ & as e & $\begin{array}{r}\text { Divisão de } t \\
\text { que não ger } \\
\text { excessiv } \\
\text { estressa }\end{array}$ & $\begin{array}{l}\text { ho, o } \\
\text { mos } \\
\text { a }\end{array}$ & & - \\
\hline \multicolumn{7}{|c|}{ RISCO DE ACIDENTE } \\
\hline Agentes & Fonte Gerador & & $\begin{array}{r}\text { Medidas de } \\
\text { exister }\end{array}$ & role & Medidas & ontrole Propostas \\
\hline \multicolumn{7}{|c|}{ Não foi encontrado nenhum agente causador } \\
\hline
\end{tabular}

QUADRO 4: Reconhecimento de riscos setor operacional

Fonte: Autor, 2018 


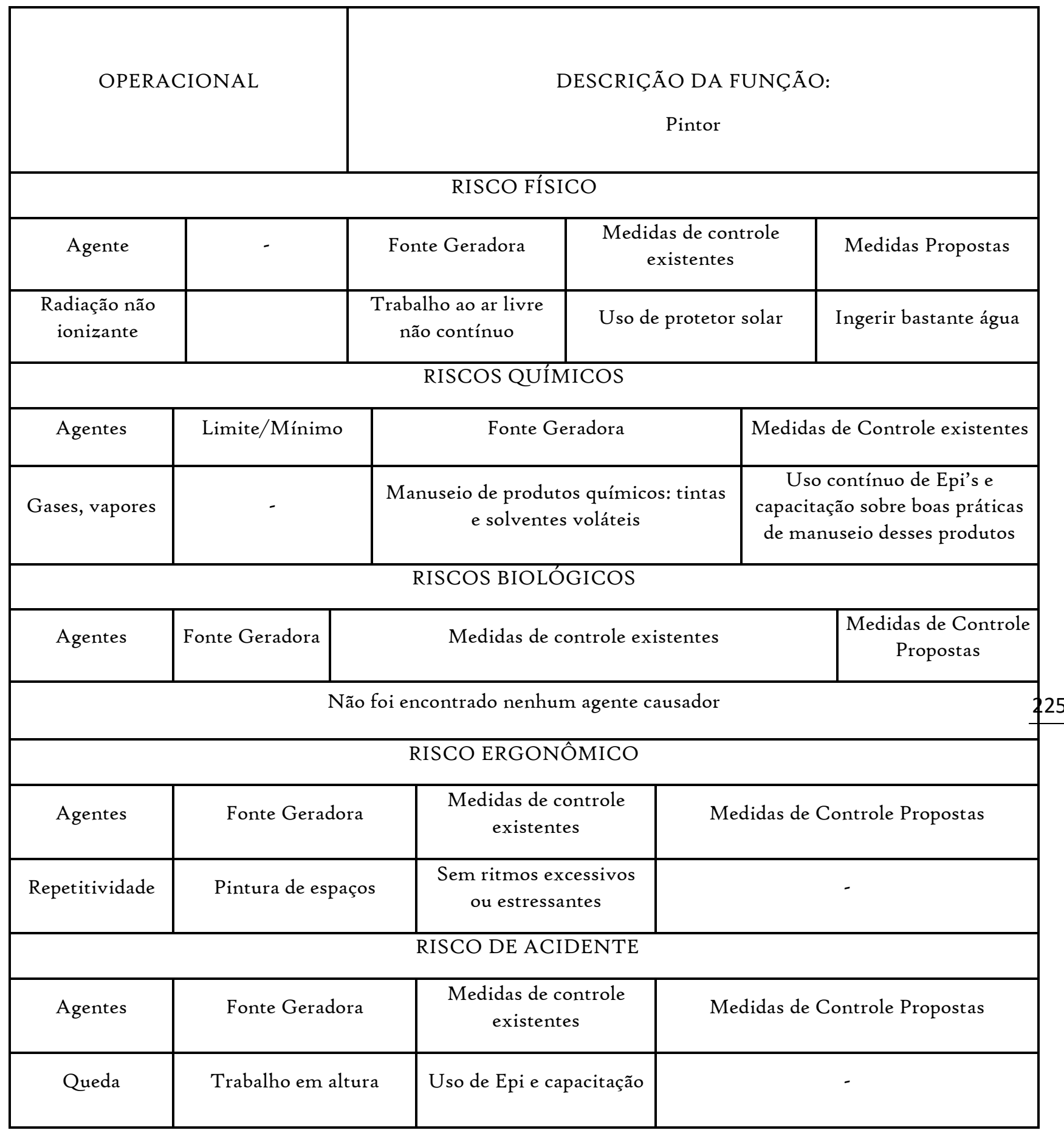

QUADRO 5: Reconhecimento de riscos setor operacional

Fonte: Autor, 2018

Baseado nessas informações, há o mapa de riscos, que demonstra de forma objetiva e prática, através da planta baixa da empresa, seus riscos identificados, bem como o grau de relevância. Este deve obrigatoriamente ser impresso e exposto em local de fácil acesso: 


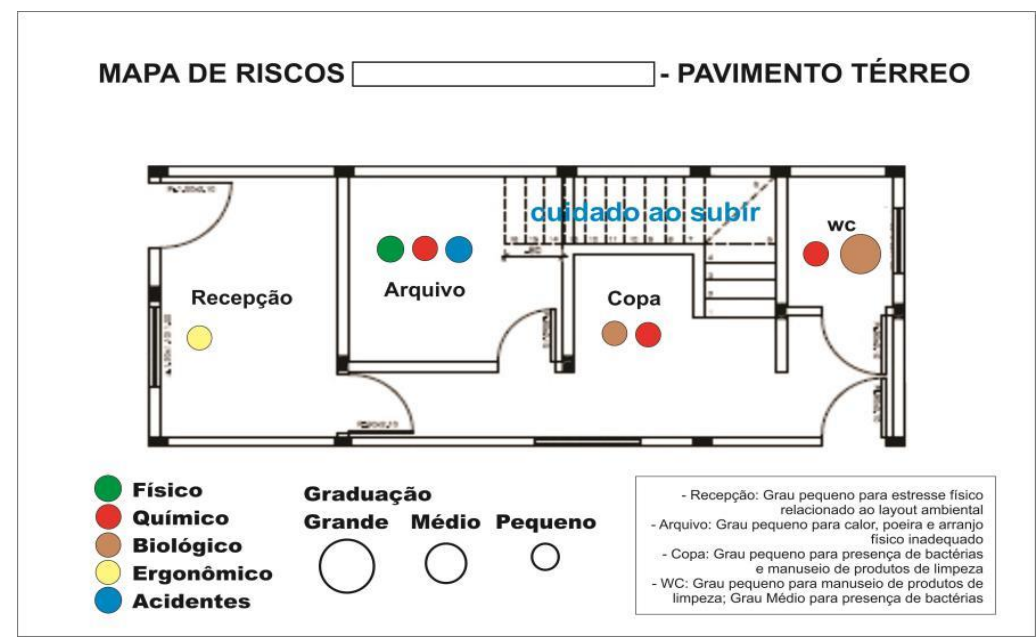

FIGURA I: MAPA DE RISCOS

Fonte: Autor, 2018

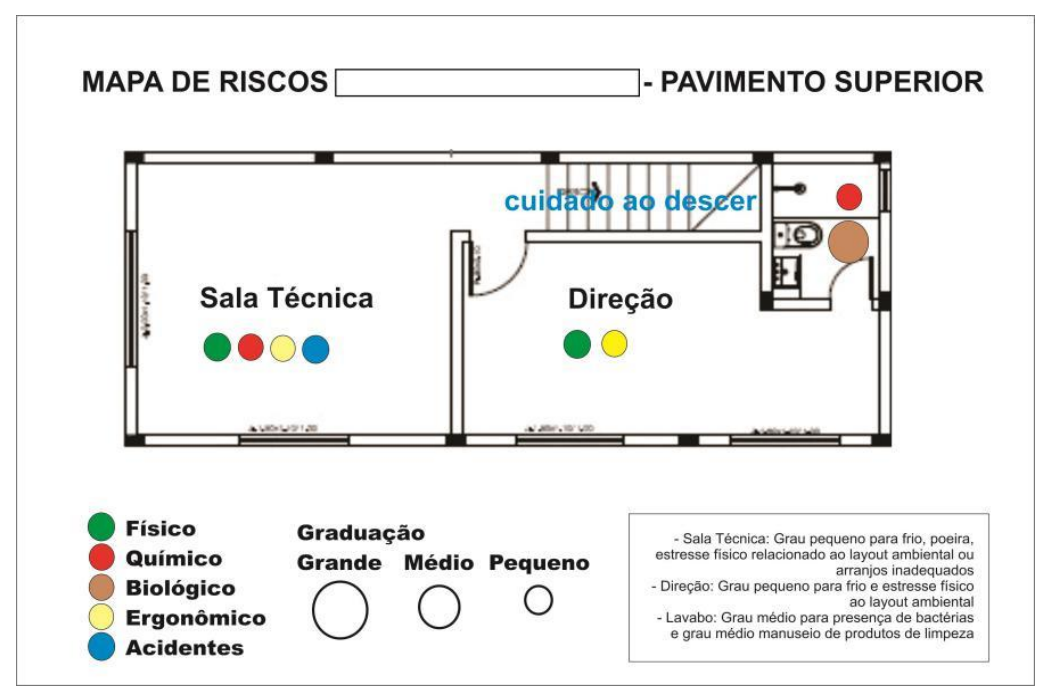

FIGURA 2: MAPA DE RISCOS

Fonte: Autor, 2018

Deste modo, para o layout tem-se, conforme NR 23: Sinalização de saída, junto à porta da recepção e deve estar ao nível da altura da porta; material sinalizador de degrau: fita adesiva ou carpete emborrachado, o que dificulta escorregões; indicação de corrimão; no pavimento superior, sinalização próxima ao vão da escada, indicando a descida. Conforme a NBR ${ }_{2} 693$, tem-se: Um extintor tipo ABC, no pavimento térreo, fixado na parede a I,6o de altura, bem como sua sinalização. A área em que esse for alocado deve ter um espaço de pelo menos $\mathrm{Im} \times$ Im desobstruído e o mesmo deve acontecer para a instalação no pavimento superior da empresa. 


\section{Conclusão}

Diante do exposto, conclui-se que um PPRA é um Programa dinâmico, ou seja, pode ser revisado sempre e quando for necessário, devendo ser periodicamente atualizado, acrescentando registros, catálogos de EPIs, ordens de serviço, entre outros. Por esse motivo, deve-se ainda incluir um calendário de ações afirmativas de promoção da saúde e segurança do trabalho, com datas previstas para tais atividades, como: capacitações e palestras, mas sempre realizadas por profissionais habilitados.

\section{Referências}

ALMEIDA, I.M. Introdução à abordagem de concepções de acidentes e suas implicações na análise desses eventos. Caminhos da análise de acidentes do trabalho, p. $57-66,2003$.

ASSUNÇÃO, A.A. Uma contribuição ao debate sobre as relações saúde e trabalho. Ciênc. Saúde Coletiva, vol. 8, n. 4, p. 1005- I018, 2003.

CHAVES, S.C.L.; SANTANA, V.S.; LEÃO, I.C.M.; SANTANA, J.N.; ALMEIDA, L.M.A. Determinantes da implantação de um programa de segurança e saúde no trabalho. Rev. Panam Salud Publica, 2009

ENIT/BR. Normas Regulamentadoras. Disponível em: <https://enit.trabalho.gov.br/portal/index.php/seguranca-e-saude-no-trabalho/sst$\mathrm{menu} /$ sst-normatizacao/sst-nr-portugues?view=default $>$ Acesso em: I5 dez. 2019.

BRASIL, LEI N. 6.514. Alteração do Capítulo V do Titulo II da Consolidação das Leis do Trabalho, relativo à segurança e medicina do trabalho e dá outras providências. Disponível em: 〈http://www.planalto.gov.br/ccivil_03/leis/16514.htm> Acesso em: is out. 2019.

NBR 12693 - Sistemas de proteção por extintores de Incêndio. Disponível em:<http://pcpreventivo.com.br/img/normas/nbri2693sistemasdeproteoporextintor esdenopw-I206I3141221-phpappoi.pdf $>$ Acesso em: 20 dez. 2019. 